\title{
Permeabilization of the mitochondrial inner membrane during apoptosis: impact of the adenine nucleotide translocator
}

\author{
HLA Vieira ${ }^{1}$, D Haouzi ${ }^{1}$, C El Hamel ${ }^{1}$, E Jacotot ${ }^{1}$, \\ A-S Belzacq ${ }^{2}$, C Brenner ${ }^{2}$ and G Kroemer*,1 \\ ${ }^{1}$ Centre National de la Recherche Scientifique, UMR1599, Institut Gustave \\ Roussy, 39 rue Camille-Desmoulins, F-94805 Villejuif, France \\ ${ }^{2}$ Centre National de la Recherche Scientifique, UMR6022, Université \\ Technologique de Compiègne, F-60205 Compiègne, France \\ * Corresponding author: G Kroemer, 19 rue Guy Môquet, B.P. 8, F-94801 \\ Villejuif, France. Tel: 33-1-49 5835 13; Fax: 33-1-49 5835 09; \\ E-mail: kroemer@infobiogen.fr
}

Received 15.7.00; accepted 14.9.00

Edited by $\mathrm{G}$ Kroemer

\begin{abstract}
Mitochondrial membrane permeabilization can be a rate limiting step of apoptotic as well as necrotic cell death. Permeabilization of the outer mitochondrial membrane (OM) and/or inner membrane (IM) is, at least in part, mediated by the permeability transition pore complex (PTPC). The PTPC is formed in the IM/OM contact site and contains the two most abundantIM and OM proteins, adenine nucleotide translocator (ANT, in the IM) and voltage-dependent anion channel (VDAC, in the OM), the matrix protein cyclophilin D, which can interact with ANT, as well as apoptosis-regulatory proteins from the $\mathrm{Bax} / \mathrm{Bcl}-2$ family. Here we discuss that ANT has two opposite functions. On the one hand, ANT is a vital, specific antiporter which accounts for the exchange of ATP and ADP on IM. On the other hand, ANT can form a non-specific pore, as this has been shown by electrophysiological characterization of purified ANT reconstituted into synthetic lipid bilayers or by measuring the permeabilization of proteoliposomes containing ANT. Pore formation by ANT is induced by a variety of different agents (e.g. $\mathrm{Ca}^{2+}$, atractyloside, thiol oxidation, the pro-apoptotic HIV-1 protein Vpr, etc.) and is enhanced by Bax and inhibited by $\mathrm{Bcl}-2$, as well as by ADP. In isolated mitochondria, pore formation by ANT leads to an increase in IM permeability to solutes up to $1500 \mathrm{Da}$, swelling of the mitochondrial matrix, and $\mathrm{OM}$ permeabilization, presumably due to physical rupture of $\mathrm{OM}$. Although alternative mechanisms of mitochondrial membrane permeabilization may exist, ANT emerges as a major player in the regulation of cell death. Cell Death and Differentiation (2000) 7, 1146-1154.
\end{abstract}

Keywords: apoptosis; Bcl-2; mitochondria; permeability transition
Abbreviations: ANT, adenine nucleotide translocator; IM, inner membrane; OM, outer membrane; PTPC, permeability transition pore complex; SIMPs, soluble intermembrane space proteins; VDAC, voltage dependent anion channel

\section{Introduction}

Mitochondrial membrane permeabilization (MMP) appears to be a near-to-general phenomenon associated with apoptosis. ${ }^{1-3}$ Schematically, three phases of the apoptotic process can be distinguished. During a pre-mitochondrial phase proapoptotic second messengers are activated and factors acting on mitochondrial membranes accumulate and/or translocate to mitochondria. Prominent pro-apoptotic proteins directly acting on mitochondria include the pro-apoptotic members of the Bcl-2/Bax family, as well as kinases and phosphatases which induce covalent modification of $\mathrm{Bcl}-2 /$ Bax family members, thereby influencing their function and/or subcellular localization. p53 has also recently been shown to translocate to mitochondria. ${ }^{4}$ Non-protein factors acting on mitochondria include $\mathrm{Ca}^{2+}$, reactive oxygen species, $\mathrm{NO}$, and ganglioside GD3 (reviewed $\mathrm{in}^{3,5-7}$ ). During the mitochondrial phase, MMP occurs, presumably through a limited set of mechanisms which are discussed in this special issue of Cell Death and Differentiation. Finally, during the post-mitochondrial phase, the functional consequences of MMP namely bioenergetic failure and/or release of potentially harmful proteins normally sequestered in mitochondria causes cell death.

The signs of MMP include the release of soluble proteins from the mitochondrial intermembrane space (e.g. cytochrome $c$, apoptosis inducing factor) through the outer membrane (OM), as well as a partial permeabilization of the inner membrane (IM) for solutes up to $\sim 1500 \mathrm{Da}$, leading to a reduction of the mitochondrial transmembrane potential $\left(\Delta \Psi_{\mathrm{m}}\right)$. IM permeabilization appears to be a less constant feature of apoptosis than OM permeabilization. Although cytochrome $c$ release through $\mathrm{OM}$ is mostly associated with a permanent loss of $\Delta \Psi_{\mathrm{m}}{ }^{8}$ this $\Delta \Psi_{\mathrm{m}}$ reduction may be transient, indicating IM 'resealing'. ${ }^{9-11}$ Moreover, in some cases cytochrome $c$ release may occur in cells whose mitochondria have an apparently normal ${ }^{1,12}$ or even an increased $\Delta \Psi_{\mathrm{m} \cdot{ }^{13}}$

The mechanism of OM permeabilization is controversial. OM permeabilization has been proposed to occur independently from that of IM, e.g. due to the OM insertion and oligomerization of Bax-like molecules, which may or may not cooperate with the OM protein VDAC (voltagedependent anion channel) to form large protein-permeable 
conduits. ${ }^{14,15}$ Alternatively, primary IM permeabilization to small ions and water may cause osmotic matrix swelling and consequent OM rupture, resulting because the surface area of the IM with its folded christae exceeds that of the OM. Accordingly, matrix swelling and herniation of IM through $\mathrm{OM}$, with consequent physical rupture of $\mathrm{OM}$, has been observed at the ultrastructural level in a variety of models of apoptosis (Table 1), including in hepatocytes exposed to CD95 crosslinking in vivo. ${ }^{16}$ Of note, matrix swelling is a feature of apoptosis which can only be observed transiently, before the cytoplasm (including mitochondria) undergoes apoptotic shrinkage. ${ }^{17}$

The present review will focus on one particular molecule involved in MMP, namely the IM protein ANT (adenine nucleotide translocator). We will advance several arguments why we believe ANT to be a key player in the regulation of cell-death associated MMP.

\section{Normal structure and function of ANT}

ANT, a $\sim 30 \mathrm{kDa}$ protein exclusively localized to the IM, is involved in the specific exchange of ADP and ATP. ${ }^{18}$ ANT is an antiporter whose function is strictly required for ATP produced on the matrix side of IM by the $F_{0 / 1}$ ATP synthase to be exported to the rest to the cell. Genetic inactivation of ANT therefore results into a severe metabolic impairment. ${ }^{19}$ Transport is driven by the $\Delta \Psi_{\mathrm{m}}$ leading to the net import of one positive charge per reaction cycle (exchange of $\mathrm{ATP}^{4-}$ by $\mathrm{ADP}^{3-}$ ). In particular circumstances, when the respiratory chain (which normally generates the $\Delta \Psi_{\mathrm{m}}$ ) is blocked, ANT may function in the opposite direction and import ATP into the matrix while exporting ADP (a reaction which then contributes to the generation of the $\left.\Delta \Psi_{\mathrm{m}}\right)$, ATP consumption being mediated by the $F_{0 / 1}$ ATP synthase functioning in its ATPase mode (which pumps protons out of the matrix while consuming ATP, thus generating a $\Delta \Psi_{\mathrm{m}}$ ). As a result, the activity of ANT and $F_{0 / 1}$ ATP synthase may be expected to be tightly coupled among each other.
In humans and rodents, three and two ANT isoforms exist, respectively, and are expressed in a strictly tissuespecific fashion. ${ }^{20}$ The human ANT2 isoform is selectively expressed in proliferating cells. ${ }^{21}$ In non-proliferating cells ANT2 expression appears to be negatively regulated by the general transcription factor $\mathrm{Sp} 1,{ }^{22}$ as well as specific hexanucleotide silencer element in the ANT2 promoter. ${ }^{23}$ All ANT isoforms are members of the family formed by the carriers of the mitochondrial IM. Proteins from this family are characterized by a tripartite structure with three repeated segments of about 100 amino acid residues each. $^{24-26}$ Each of the repeated segments contains two peaks of hydrophobicity corresponding to two transmembrane helices (six in total), separated by a stretch of amino acids that protrude to the matrix (three in total). The $\mathrm{N}$ terminus and the C-terminus of the ANT molecule are located on the intermembrane face of $\mathrm{IM}$, and the linker regions between each of the repeated segments (two in total) form loops protruding into the intermembrane space. ${ }^{18}$ ANT is a basic protein whose excess cationic changes are at least partially compensated by close interaction with the acidic lipid cardiolipin, ${ }^{27}$ a lipid which is exclusively found within the IM. The native ANT is probably a dimer or an oligomer with an even number of molecules, based on the observation that a covalent tandem dimer of yeast ANT (generated by fusion of the $\mathrm{C}$-terminus of the first repeat to the $\mathrm{N}$-terminus of the second repeat) is functional. ${ }^{28}$

Two pharmacological ANT inhibitors interact with distinct binding sites of ANT. Bongkrekic acid (BA) binds to the matrix face of ANT, whereas carboxyatracyloside (or atractyloside, Atr) binds to the intermembrane side of the molecule. Interaction with BA forces ANT to adopt its mstate conformation, whereas Atr induces the c-state conformation. During the ADP/ATP exchange, the ANT molecule is thought to undergo major conformational changes, which probably are reflected by the $\mathrm{m}$ - and $\mathrm{c}$ states respectively. ${ }^{29}$ These conformational changes are

Table 1 Examples of mitochondrial swelling and outer membrane disruption in cell death

\begin{tabular}{|c|c|c|c|}
\hline Model & Swelling & $\begin{array}{c}\text { Outer membrane } \\
\text { rupture }\end{array}$ & Reference \\
\hline Apoptosis induced in vitro by IL-3 withdrawal or $\alpha$ CD95 & + & + & 75 \\
\hline Hepatocyte apoptosis induced by $\alpha$ CD95 or D-galactosamine and TNF- $\alpha$ in vivo & + & $\begin{array}{l}+ \\
+\end{array}$ & 16,78 \\
\hline Hepatocyte death induced by hydrazine chloramphenicol, or chloroform in vivo & + & N.D. & 79,80 \\
\hline Castration induced prostate cell apoptosis & + & + & 81 \\
\hline Traumatic axonal injury in vivo & + & + & 82 \\
\hline Leukocytes exposed to Pasteurella haemolytica leukotoxin & + & + & 83 \\
\hline Thymocytes treated with dexamethasone & + & N.D. & 17 \\
\hline Ischemia reperfusion of intestine & + & N.D. & 84 \\
\hline Auditory epithelial cells after injection of gentamycin & + & N.D. & 85 \\
\hline Ceramide-treated HUT78 cells & + & N.D. & 86 \\
\hline $\mathrm{H}_{2} \mathrm{O}_{2}$-stressed astrocytes & + & N.D. & 87 \\
\hline Hippocampal injury by hypoglycemia & + & N.D. & 88 \\
\hline Motoneurons of mice with transqenic SOD-1 mutations & + & N.D. & 62 \\
\hline NO-treated HeLa and PC12 cells & + & N.D. & 89 \\
\hline Capsaicine-induced neuronal death in neonatal rats, in vivo & + & N.D. & 90 \\
\hline
\end{tabular}

N.D. denotes not detected 
likely to involve the rearrangement of charged sites within the membrane..$^{30,31}$ On the matrix side of ANT, ADP is likely to interact with the second matrix loop, since Lys162 of the bovine heart ANT interacts with radiolabelled 2azido-ADP. ${ }^{18}$ Moreover, 7-azido-5-isopropyl-acridone, which reacts with Cys159, displaces ADP from its binding site. $^{32}$ Oxidative stress induced by tert-butylhydroperoxide or diamide (which crosslinks Cys56 in the first matrix loop) reduces the affinity of ANT for ADP. ${ }^{33}$ Monovalent derivatization of Cys56 by the thiol-reactive agent methyl methanethiosulfonate causes an irreversible extrusion of the first loop facing the matrix and freezes the ANT in its mstate conformation. ${ }^{34}$ Intermolecular crosslinking of Cys56 residues by bifunctional dimaleimides only causes dimerization of ANT in its m-state, but not in its c-state, ${ }^{35}$ and inhibits the antiporter activity of ANT. Dimerization can be achieved with dimaleimide in which the distance between the two maleimide groups ranges from 8 to $17 \AA$, with an optimum at $12 \AA$, suggesting a (regulatory?) fluctuation of the loop containing Cys56. ${ }^{35}$

\section{ANT as a pore-forming protein}

The biochemical features of ANT can be best studied by reconstituting the purified protein into synthetic lipid bilayers, either in proteoliposomes or in planar membranes. Hydrophilic compounds with a relative mass $<1500 \mathrm{Da}$ (e.g. malate, ${ }^{3} \mathrm{H}$-glucose, calcein, 4-methylumbelliferone phosphate) can be encapsulated in proteoliposomes and their release can be quantitated via a variety of different techniques (enzymatically in the case of malate, radioactivity in the case of ${ }^{3} \mathrm{H}$-glucose, fluorescence dequenching in the case of calcein, alkaline phosphatase-mediated conversion to a fluorescent product, 4-methylumbelliferone, in the case of 4methylumbelliferone phosphate).$^{36-38}$ Using this experimen- tal set-up, it has been shown that ANT proteoliposomes but not control liposomes lacking ANT become permeabilized in response to atractyloside, ${ }^{37} \mathrm{Ca}^{2+}, 36$ the thiol crosslinker diamide, ${ }^{38}$ the ROS donor tert-butylhydroperoxide, Bax, ${ }^{37}$ and viral protein $\mathrm{R}(\mathrm{Vpr})$ encoded by human immunodeficiency virus-1 (HIV-1). ${ }^{39}$ These data indicate that ANT can mediate permeabilization in response to several agents which reportedly induce mitochondrial membrane permeabilization and apoptosis. Of note, non-specific pore formation has also been reported for other members of the mitochondrial carrier family. Thus, following treatment with thiol-specific chemical reagents, the aspartate/glutamate carrier can be converted from an obligatory exchange antiporter to a channel-like uniporter. ${ }^{40}$ After deletion of a stretch of nine amino acid in the third matrix loop, uncoupling protein (UCP) becomes a nonspecific pore. ${ }^{41}$ Whether native UCP also may form a pore in a more physiological context, however, remains elusive.

Electrophysiological experiments confirm that ANT can form channels (Table 2). Single channel current measurements of excised patches with reconstituted purified ANT indicate that $\mathrm{Ca}^{2+}$ can induce the formation of large channels with multiple subconductance states varying from 70 to $600 \mathrm{pS}$, depending on the ion concentration. $^{42,43}$ Channel formation is inhibited by low $\mathrm{pH}(<5.2)$, ADP and bongkrekate. ${ }^{42}$ Single channel recordings revealed that ANT can also form relatively small channels (30 pS) in response to its ligand Atr. ${ }^{43} \mathrm{~A}$ mixture of Bax and ANT (molar ratio 1:4) has a higher probability of Atrinduced pore openings and exhibits two different conductance levels (30 and $80 \mathrm{pS}$ ), as well as cation specificity (whereas Bax alone forms an anion-selective channel). When employed at relatively low doses (1 $\mathrm{nM})$, Bax does not yield any major macroscopic conductance, unless combined with ANT treated with Atr. Thus, the combination of $\mathrm{ANT}+\mathrm{Atr}+\mathrm{Bax}$ forms a much more efficient membrane

Table 2 Electrophysiological characteristics of ANT, Bax, and Bcl-2

\begin{tabular}{|c|c|c|c|c|c|}
\hline Protein (s) & Unit conductance (pS) & $\mathrm{pH}$ & Salt (nM) & Selectivity & Reference \\
\hline \multirow[t]{6}{*}{ Bax } & $5.6 ; 26 ; 80 ; 180 ; 250 ; 2000$ & 7.0 & $125 \mathrm{NaCl}$ & Cation & 91 \\
\hline & $27 ; 77$ & 4.0 & $125 \mathrm{NaCl}$ & Cation & 91 \\
\hline & 329 & 7.0 & $450 / 150 \mathrm{KCl}$ & Anion & 92 \\
\hline & 22 to 730 & 4.0 & $450 / 150 \mathrm{KCl}$ & & \\
\hline & 200 & 7.4 & $100 \mathrm{KCl}$ & Anion & 43 \\
\hline & $20 ; 250$ & 7.4 & $500 / 100 \mathrm{NaCl}$ & Cation & 93 \\
\hline \multirow[t]{4}{*}{$\mathrm{Bcl}-2$} & $20 ; 40 ; 90$ & 7.4 & $500 \mathrm{KCl}$ & Cation & 46 \\
\hline & 80 to $>1900$ & 4.0 & $450 / 150 \mathrm{KCl}$ & Cation & 92 \\
\hline & 1080 & 7.0 & $450 / 150 \mathrm{KCl}$ & & \\
\hline & 35 & 7.4 & $100 \mathrm{KCl}$ & Cation & 43 \\
\hline \multirow[t]{2}{*}{ ANT } & 0 & 7.2 & $100 \mathrm{KCl}$ & - & 42 \\
\hline & 0 & 7.4 & $100 \mathrm{KCl}$ & - & 43 \\
\hline \multirow[t]{2}{*}{$\mathrm{ANT}+\mathrm{Ca}^{2+}$} & 300 to 600 & 7.2 & $100 \mathrm{KCl}$ & Cation & 42 \\
\hline & $70: 250$ & 7.4 & $100 \mathrm{KCl}$ & Cation & 43 \\
\hline ANT+Atr & 30 & 7.4 & $100 \mathrm{KCl}$ & Cation & 43 \\
\hline ANT+Bax & 200 & 7.4 & $100 \mathrm{KCl}$ & - & 43 \\
\hline $\mathrm{ANT}+\mathrm{Bax}+\mathrm{Atr}$ & $30 ; 80$ & 7.4 & $100 \mathrm{KCl}$ & Cation & 43 \\
\hline ANT+Bax $\Delta \alpha 5 / 6+$ Atr & 30 & 7.4 & $100 \mathrm{KCl}$ & - & 43 \\
\hline ANT+Bax DIGDE+Atr & 30 & 7.4 & $100 \mathrm{KCl}$ & - & 43 \\
\hline $\mathrm{ANT}+\mathrm{Bcl}-2+\mathrm{Atr}$ & 0 & 7.4 & $100 \mathrm{KCl}$ & - & 43 \\
\hline ANT+Bcl-2 $\Delta \alpha 5 / 6+$ Atr & 30 & 7.4 & $100 \mathrm{KCl}$ & - & 43 \\
\hline ANT+Bcl-2 G145A+Atr & 0 & 7.4 & $100 \mathrm{KCl}$ & - & 43 \\
\hline $\mathrm{ANT}+\mathrm{Bax}+\mathrm{Bcl}-2+\mathrm{Atr}$ & 0 & 7.4 & $100 \mathrm{KCl}$ & - & 43 \\
\hline
\end{tabular}


permeabilizing channel than do the combinations $A N T+A t r$, ANT+Bax, or Atr+Bax. The ANT/Bax cooperation is not observed when wild type Bax is replaced by two mutant proteins which have lost their apoptogenic potential: ${ }^{44,45}$ Bax $\triangle I G D E$, which lacks a homodimerization domain in the $\mathrm{BH} 3$ region, and Bax $\Delta \alpha 5 / 6$, which lacks a putative pore forming domain. Preincubation of ANT with its physiological ligand ATP completely inhibits the channel activity mediated by ANT+Atr+Bax. ${ }^{43}$ The combination of ANT plus Bcl-2 (molar ratio $1: 1$ ) results in a virtual cessation of Atr-induced ion movement indicative of the closure of both ANA and Bcl-2 channels. ${ }^{43}$ If $\mathrm{Bcl}-2$ is replaced by a mutant protein (Bcl-2 $\Delta \alpha 5 / 6$ ) lacking a putative pore formation domain, ${ }^{45,46}$ the inhibition of ANT-mediated conductance is suboptimal (Table 2). In conclusion, Bax and ANT can cooperate by forming a new class of channels which acquire distinct electrophysiological properties as well as a far higher probability of opening than either of the two compounds on its own. Moreover, Bcl-2 and ANT exhibit mutual inhibition of ion channel formation in vitro.

\section{ANT-interacting, apoptosis-regulatory proteins}

ANT can interact with a large number of proteins involved in the regulation of MMP and apoptosis (Figure 1). Thus, ANT is part of a multiprotein ensemble, the permeability transition pore complex (PTPC), which forms in the contact site between IM and OM. ${ }^{47}$ In this section, we will briefly enumerate proteins that have been shown to physically interact with ANT.

\section{Cyclophilin D}

Cyclophilin $D$ is the mitochondrial target of cyclosporin $A$ (CsA) and the non-immunosuppressive CsA derivative and $\mathrm{N}$ methyl-4-Val-CsA, both of which inhibit the PTPC and can

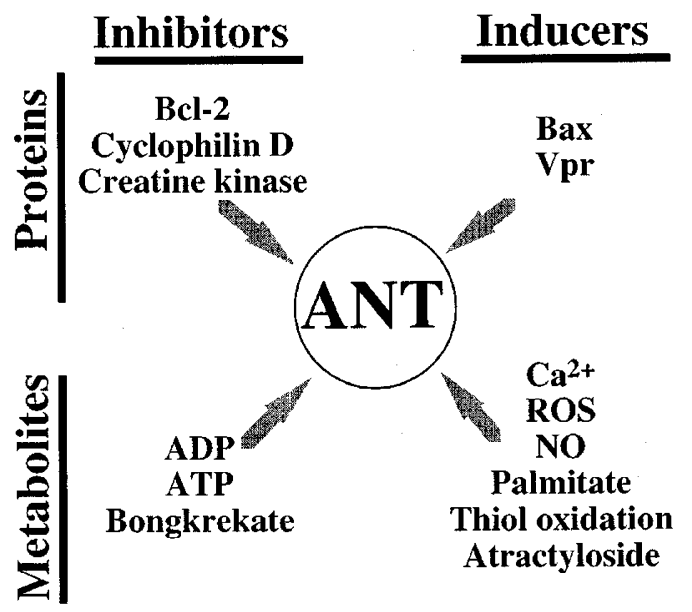

Figure 1 Molecules influencing ANT-mediated pore formation in chemically defined systems. The upper part lists proteins affecting the pore function of ANT, whereas the lower part focuses on non-protein molecules. Data are from references ${ }^{36-39,43,60}$ inhibit apoptosis in various in vitro and in vivo models. ${ }^{16,48}$ When immobilized on a column, purified recombinant cyclophilin D specifically retains ANT among triton-solubilized IM preparations ${ }^{49}$ and ANT plus VDAC among whole mitochondrial membrane extracts. ${ }^{50}$ Binding of cyclophilin D to purified mitochondrial IM is inhibited by CsA and enhanced by treatment with tert-butylhydroperoxide and by diamide, ${ }^{51}$ suggesting that the cyclophilin-D-ANT interaction favors mitochondrial membrane permeabilization.

\section{Proteins from the $\mathrm{Bcl}-2 / \mathrm{Bax}$ family}

ANT has been shown to interact directly with $\mathrm{Bcl}-2, \mathrm{Bcl}-\mathrm{XL}$, Bax and Bak by three independent techniques: co-purification, co-immunoprecipitation and yeast-two-hybrid screening. ${ }^{37,47}$ This latter technique revealed that a short stretch of human ANT2 (amino acids 105-156) suffices for the interaction with $\mathrm{Bcl}-2$-related proteins. ${ }^{37}$ As discussed above, it appears that Bax can cooperate with ANT to form pores, whereas Bcl-2 prevents the ANT-dependent pore formation in synthetic membranes. Bax-induced MMP can be inhibited by the ANT ligand bongkrekic acid, ${ }^{37,52}$ underlining the probable relevance of the ANT-Bax interaction.

\section{VDAC}

VDAC binds to ANT. ${ }^{53}$ VDAC is generally considered as the principal OM protein allowing for the OM transit of metabolites $<5000 \mathrm{kDa}$. VDAC has been suggested to be the mitochondrial target of the pro-apoptotic proteins Bax and $\mathrm{Bcl}-2$, which would allow VDAC to form a cytochrome $c$ permeant conduit. ${ }^{14}$ Intriguingly, the VDAC1 gene is transcriptionally upregulated in a model of $\gamma$-irradiationinduced apoptosis. ${ }^{54}$

\section{Peripheral benzodiazepin receptor}

The peripheral benzodiazepin receptor (PBR, also called mitochondrial diazepam binding receptor) co-purifies with ANT and VDAC. ${ }^{55}$ PBR, an OM protein, is a pharmacological target for cytotoxic drugs. Thus PBR ligands such as PK111195 (1-(2-chlorophenyl)-N-methyl-N-(1-methylpropyl)isoquinolinecarboxamide), FGIN-I-27 (N,B-di-n-hexyl 2-(4fluorophenyl)indole-3-acetamide), and chlorodiazepam enhance the apoptogenic effects of a variety of agents including TNF, ${ }^{56}$ ceramide, doxorubicin, etoposide, ${ }^{57}$ arsenite, ${ }^{58}$ or lonidamine ${ }^{59}$ and overcome the cytoprotective effects of $\mathrm{Bcl}-$ $2^{57-59}$

\section{Creatine kinase}

Creatine kinase co-purifies with ANT and VDAC. It appears that the creatine kinase octamer can inhibit pore formation by ANT. ${ }^{60}$ Creatine and creatine phosphate may have cytoprotective effects in some models of cell death. ${ }^{61,62}$

\section{The protein kinase src}

An N-terminally myristylated peptide derived from src binds to ANT in vitro. ${ }^{63}$ However, at present it is not clear whether 
intact protein kinases from the src family bind to mitochondria in intact cells.

\section{Viral effectors}

The anti-apoptotic protein VMIA, a product of the cytomegalovirus UL37 gene, has been shown to specifically interact with ANT. ${ }^{64}$ Similarly, viral protein $\mathrm{R}(\mathrm{Vpr})$, a pro-apoptotic protein encoded by human immunodeficiency virus-1 (HIV-1) specifically binds to ANT with an affinity in the nanomolar range. ${ }^{39}$

\section{Pharmacological and genetic evidence that ANT participates in cell death regulation in intact cells}

Bongkrekic acid, a specific ANT ligand which prevents pore formation by ANT, can inhibit the induction of apoptosis in a number of different experimental systems (Table 3). Pharmacological evidence suggests that ANT itself is the target of several apoptosis-inducing agents. Thus, MMP and apoptosis induction by means of the thiol-crosslinking agent diamide correlates with oxidation of Cys56 of ANT, as well as with ANT dimerization. ${ }^{38,65}$ Fatty acid anions (e.g. palmitate or stearate), including a non-metabolizable analogue $\beta, \beta^{\prime}$-methyl substituted hexadecane $\alpha, \omega$-dioic acid, uncouple mitochondria via an effect on ANT, ${ }^{66}$ who facilitates their electrophoretic translation from the inner to the outer leaflet of IM. ${ }^{67}$ Palmitate also induces apoptosis when added to intact cells and this effect is inhibited by BA, indicating the involvement of ANT. ${ }^{68}$ Some non-steroidal anti-inflammatory drugs (e.g. diclofenac) both induce PTPC opening and inhibit ANT activity in purified mitochondria. ${ }^{69}$ The unsaturated aldehydes 4-hydroxynonenal and 4-hydroxyhexenal, which arise as a by-product of lipid peroxidation and have potent cytotoxic and MMP-inducing activities, also inhibit the antiport activity of ANT reconstituted into liposomes. ${ }^{70}$

More convincingly, genetic experiments confirm the participation of ANT in the control of cell death. Yeast cells in which the three ANT isoenzymes have been inactivated by homologous recombination are relatively resistant against killing by $\mathrm{Bax}^{37}$ and $\mathrm{Vpr}^{39}$ Inactivation of the ANT isoenzyme 2 alone suffices to render yeast cells relatively resistant to Bax. ${ }^{71}$ Inactivation of $F_{1 / 0}$ ATPase subunits also yields Bax-resistant cells. ${ }^{71,72}$ On theoretical grounds, it may be speculated that the suppression of mitochondrial ATP synthesis/consumption should paralyse the antiporter function of ANT (and perhaps reduce the probability that ANT adopts the pore-forming conformation). Transfection-enforced overexpression of mouse ANT1 (but not ANT2) induces apoptosis in mammalian cells. This is not due to a non-specific toxic effect of the overexpressed protein, because ANT1-induced apoptosis is abolished by co-transfection with cDNA coding for cyclophilin D. ${ }^{73}$ The $\mathrm{N}$-terminal half of ANT-1 (aa 1-141) conserves its cytocidal potential. However, further truncation of ANT-1, from aa 102 to the C-terminus, abolishes its apoptogenic effect. Hence, a critical region of ANT1 (aa 102-141) is required for apoptosis induction. Intriguingly, this region overlaps with the Bcl-2/Bax binding site of ANT (aa 105$156)^{37}$ and contains a Vpr-binding peptide motif (WXXF; aa $110-114 ;{ }^{74}$ ) within the C-terminal half of the first intermembrane loop (aa 103-115) (Figure 2). It is tempting to speculate that the apoptosis-regulatory domain of the ANT protein (aa 103-142), which comprises the third transmembrane domain (aa 116-134), may participate in ANT-mediated pore formation. Intriguingly, the Bcl2/Bax binding site also overlaps with the region of ANT (aa 148-156) in which the three ANT isoforms exhibit the strongest level of divergence, suggesting an iso-form specific regulation of ANT at this level.

\section{Open questions and perspectives}

At least in some models of apoptosis, a transient $\Delta \Psi_{\mathrm{m}}$ increase precedes the later $\Delta \Psi_{\mathrm{m}}$ collapse. ${ }^{75}$ According to a recent study, ${ }^{76}$ overexpression of Bax induces alkalinization of the mitochondrial matrix accompanied by cytosolic acidification, ${ }^{76}$ as well as an increase in the $\Delta \Psi_{m}$ before the $\Delta \Psi_{\mathrm{m}}$ drops. ${ }^{76}$ This effect is observed both in mammalian and in yeast cells and can be recapitulated in mammalian cells exposed to the universal apoptosis inducer staurosporin. ${ }^{76}$ Given the fact that Bax can inhibit the ATP/ADP antiporter function of ANT (A-S Belzacq and C Brenner, unpublished

Table 3 Models of apoptosis inhibited by the ANT ligand bongkrekic acid

\begin{tabular}{lc}
\hline Model of cell death induction & Reference \\
\hline Glucocorticoid receptor occupancy of thymocytes & 94 \\
Protoporphyrin IX treatment of thymocytes & 95 \\
Microinjection of recombinant Bax protein into fibroblasts & 37 \\
B-cell receptor crosslinking in WEHI-231 cells & 96 \\
TNF-induced killing of L929 cells & 97 \\
TNF-induced apoptosis of primary hepatocytes & 98 \\
$\mathrm{CD} 95$ crosslinking of neutrophil granulocytes & 99 \\
$\mathrm{H}_{2} \mathrm{O}_{2}$ treatment of T cells & 100 \\
Betulinic acid acting on neuroblastoma cells & 101 \\
Valinomycin added to BAF-3 pre-B cells & 102 \\
NMDA-induced apoptosis of cerebrocortical neurons & 103 \\
Palmitate or tributylin treatment of Jurkat cells & 68,104 \\
Osteoclast anoikis & 105 \\
Sindbis virus infection & 106 \\
Vpr-induced killing of Jurkat cells & 39 \\
\hline
\end{tabular}

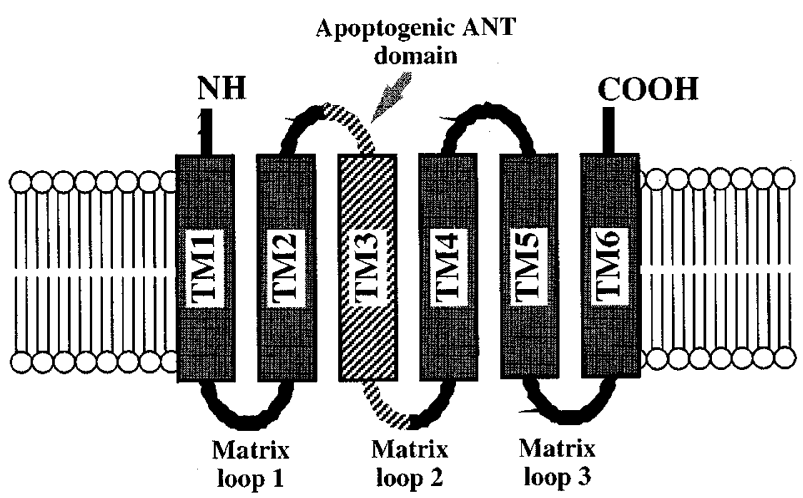

Figure 2 Topology of ANT in the inner membrane. TM, transmembrane 
observations), and that the ATP/ADP exchange reaction is compromised in mitochondria from pre-apoptotic cells, ${ }^{77}$ the following scenario becomes plausible (Figure 3): Early during apoptosis, Bax (and perhaps other pro-apoptotic members of the Bcl-2 family) would translocate to mitochondria and interact with ANT to inhibit its antiporter activity, before facilitating ANT-mediated pore formation. Indeed, pore formation by Bax+ANT in artificial membranes requires the action of additional factors (e.g. atractyloside, Vpr) which impinge on the conformation of ANT. ${ }^{37,39,43}$ As a net result of Bax-mediated antiporter inhibition, ATP would accumulate in the matrix, while matrix ADP would decline until the $F_{1 / 0}$ ATPase would be forced to operate in its ATPase mode, thereby increasing the $\Delta \Psi_{\mathrm{m}}$ and generating phosphate (which via activation of the hydroxide/phosphate carrier would cause matrix alkalinization). Accordingly, $F_{1 / 0}$ ATPase inhibition by oligomycin prevents the bax-induced $\Delta \Psi_{m}$ increase, matrix alkalinization, cytosolic acidification, and apoptosis. ${ }^{76}$ During later stages of the process, matrix alkalinization, local imbalances in the ATP/ADP concentration, increases in the production of ROS etc. would favor pore formation by ANT, aided by Bax, thereby favoring the $\Delta \Psi_{\mathrm{m}}$ loss and complete loss of mitochondrial function. This scenario provides an exciting working hypothesis (Figure 3 ) which fits well the existing experimental data, yet requires further exploration in cell-free systems.

Although ANT is probably a major pore-forming/poreregulating protein involved in the control of apoptosis, it appears clear that other proteins contained within the PTPC (VDAC, Bax, Bcl-2 etc.) may also function as pore-forming units, perhaps independently of ANT. Resolving the question to which extent individual PTPC proteins can function in the control of MMP and apoptosis will require thorough investigation of their function by multiple methods, including their reconstitution into lipid bilayers and genetic modifications in mammalian cells. Furthermore, numerous questions remain without response. How is it possible that

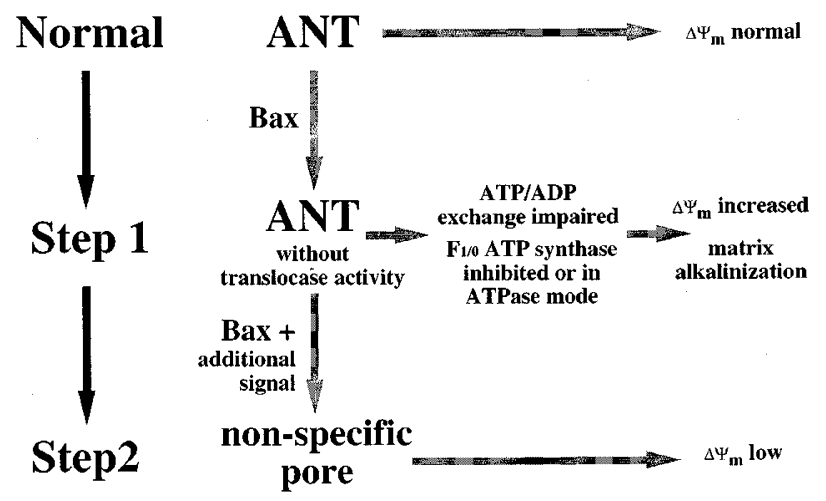

Figure 3 Hypothetical implication of ANT in a two-step model of apoptotic mitochondrial changes. During an early step (step 1), only the translocase activity of ANT would be inhibited. In contrast during a second step (step 2), ANT would convert into a non-specific pore. It is possible that the period required for the transition of step 1 to step 2 varies in different models of apoptosis, thereby creating the impression that OM permeabilization precedes or accompanies the loss of the $\Delta \Psi_{\mathrm{m}}$ proteins that are generally thought to be confined to $\mathrm{OM}$ (Bcl-2, Bax) can interact with the IM protein ANT? Do they translocate to IM? Or do protruding domains of IManchored $\mathrm{Bcl}-2 / \mathrm{Bax}$ protein (or OM-anchored ANT) bind to $\mathrm{OM}$ (or IM, respectively), within the OM/IM contact sites? Do all ANT (and VDAC) molecules participate in the control of apoptosis, or is this function restricted to the small fraction of molecules localized in the contact site? What are the exact conformational changes explaining cooperative channel formation by sessile mitochondrial proteins and Bax? What submolecular events do determine the switch from the antiporter mode to the pore-forming mode? In which specific signal transduction pathways does ANT participate at MMP, and when is it dispensable for MMP to occur? Are there differences in the pore-forming function between distinct ANT isoforms? Can other members of the mitochondrial carrier protein family participate in MMP regulation? Answering to these questions may provide tantalizing insights into cell death control mechanisms and open therapeutic avenues to the specific pharmacological manipulation of apoptosis.

\section{Acknowledgments}

This work has been supported by a special grant from the Ligue Nationale contre le Cancer, Comité Val de Marne de la Ligue contre le Cancer, as well as grants from ANRS, FRM, and the European Commission (to $G$ Kroemer). HLA Vieira receives a fellowship from the Fundação para a Ciência e a Tecnolgia PRAXIS XXI, Portugal.

\section{References}

1. Green DR and Reed JC (1998) Mitochondria and apoptosis. Science 281: 1309-1312

2. Green DR and Kroemer G (1998) The central executioner of apoptosis: mitochondria or caspases? Trends Cell Biol. 8: 267-271

3. Kroemer G and Reed JC (2000) Mitochondrial control of cell death. Nature Med. 6: $513-519$

4. Marchenko ND, Zaika A and Moll UM. (2000) Death signal-induced localization of p53 protein to mitochondria. A potential role in apoptotic signaling. J. Biol. Chem. 275: 16202-16212

5. Kroemer G (1997) The proto-oncogene Bcl-2 and its role in regulating apoptosis. Nature Med. 3: 614-620

6. Gross A, McDonnell JM and Korsmeyer SJ (1999) Bcl-2 family members and the mitochondria in apoptosis. Genes Dev. 13: 1988-1911

7. Vander Heiden MG and Thompson CB (1999) Bcl-2 proteins: Inhibitors of apoptosis or regulators of mitochondrial homeostasis? Nat. Cell Biol. 1: E209E216

8. Heiskanen KM, Bhat MB, Wang HW, Ma JJ and Nieminen AL (1999) Mitochondrial depolarization accompanies cytochrome $c$ release during apoptosis in PC6 cells. J. Biol. Chem. 274: 5654-5658

9. Petronilli V, Miotto G, Canton M, Brini M, Colonna R, Bernardi P and Di Lisa F (1999) Transient and long-lasting openings of the mitochondrial permeability transition pore can be monitored directly in intact cells by changes in mitochondrial calcein fluorescence. Biophys. J. 76: 725-734

10. Pastorino JG, Tafani M, Rothman RJ, Macineviciute A, Hoek JB and Farber JL (1999) Functional consequences of sustained or transient activation by Bax of the mitochondrial permeability transition pore. J. Biol. Chem. 274: $31734-$ 31739

11. Szalai G, Krischnamurthy R and Hajnoczky G (1999) Apoptosis driven by IP3linked mitochondrial calcium signals. EMBO J. 18: 6349-6361 
12. Goldstein JC, Waterhouse NJ, Juin P, Evan Gl and Green DR (2000) The coordinate release of cytochrome $c$ is rapid, complete and kinetically invariant. Nat. Cell Biol. 2: 156-162

13. Van der Heiden M, Chandel NS, Schumacker PT and Thompson CB (1999) Bcl$\mathrm{XL}$ prevents cell death following growth factor withdrawal by facilitating mitochondrial ATP/ADP exchange. Mol. Cell. 3: 159-167

14. Shimizu S, Narita M and Tsujimoto $Y$ (1999) Bcl-2 family proteins regulate the release of apoptogenic cytochrome $\mathrm{c}$ by the mitochondrial channel VDAC Nature 399: 483-487

15. Eskes R, Desagher S, Antonsson B and Martinou JC (2000) Bid induces the oligomerization and insertion of Bax into the outer mitochondrial membrane. Mol. Cell. Biol. 20: 929-935

16. Feldmann G, Haouzi D, Moreai A, Durand-Schneider AM, Bringuier A, Berson A, Mansouri A, Fau D and Pessayre D (2000) Opening of the mitochondrial permeability transition pore causes matrix expansion and outer membrane rupture in Fas-mediated hepatic apoptosis in mice. Hepatology 31: 674-683

17. Dallaporta B, Marchetti $P$, de Pablo M, Maisse C, Duc HT, Metivier D, Zamzami N, Geuskens M and Kroemer G (1999) Plasma membrane potential in thymocyte apoptosis. J. Immunol. 162: 6534-6542

18. Fiore $C$, Tezeguet $V$, LeSaux A, Roux $P$, Schwimmer $C$, Dianoux AC, Noel F Lauquin GJM, Brandolin G and Vignais PV (1998) The mitochondrial ADP/ATP carrier: structural, physiological and pathological aspects. Biochimie 80: 137 150

19. Graham BH, Waymire KG, Cottrell B, Trounce JA, MacGregor GR and Wallace DC (1997) A mouse model for mitochondrial myopathy and cardiomyopathy resulting from a deficiency in the heart/muscle isoform of the adenine nucleotide translocator. Nature Genet. 16: 226-234

20. Doerner A, Pauschinger M, Badorff A, Noutsias M, Giessen S, Schulze K, Bilge J, Rauch U and Schultheiss HP (1997) Tissue-specific transcription pattern of the adenine nucleotide translocase isoforms in humans. FEBS Lett. 414:258262

21. Barath P, Luciakova K, Hodny Z, Li RG and Nelson BD (1999) The growthdependent expression of the adenine nucleotide translocase-2 (ANT2) gene is regulated at the level of transcription and is a marker of cell proliferation. Exp. Cell. Res. 248: 583-588

22. Zaid A, Li RG, Luciakova K, Barath P, Nery S and Nelson BD. (1999) On the role of the general transcription factor $\mathrm{Sp} 1$ in the activation and repression of diverse mammalian oxidative phosphorylation genes. J. Bioenerg. Biomembr. 31: $129-135$

23. Barath P, Albert-Fournier B, Luciakova K and Nelson BD (1999) Characterization of a silencer element and purification of silencer protein that negatively regulates the human adenine nucleotide translocator 2 promoter. J. Biol. Chem. 274: 3378-3384

24. Walker JE and Runswick MJ (1993) The mitochondrial transport protein superfamily. J. Bioenerg. Biomembr. 25: 435-446

25. Kuan J and Saier MHJ (1993) The mitochondrial carrier family of transport proteins: structural, functional, and evolutionary relationships. Crit. Rev. Biochem. Mol. Biol. 28: 209-233

26. Nelson DR, Lawson JE, Klingenberg M and Douglas MG (1993) Site-directed mutagenesis of the yeast mitochondrial ADP ATP translocator -6 arginines and one lysine are essential. J. Mol. Biol. 230: 1159-1170

27. Beyer K and Nuscher B (1996) Specific cardiolipin binding interferes with laveling of sulfhydril residues in the adenosine diphosphate/adenosine triphosphate carrier protein from beef heart mitochondria. Biochemistry 35 : $15784-15790$

28. Hatanaka T, Hashimoto M, Majima E, Shinohara Y and Terada H (1999) Functional expression of the tandem-repeated homodimer of the mitochondrial ADP/ATP carrier in Saccharomyces cerevisiae. Biochem. Biophys. Res. Commun. 262: $726-730$

29. Gropp T, Bustovetsky N, Klingenberg M, Muller V, Fendler K and Bamberg E (1999) Kinetics of electrogenic transport by the ADP/ATP carrier. Biophys. J. 77: $714-726$

30. Brustovetsky N, Becker A, Klingenberg M and Bamberg E (1996) Electrica currents associated with nucleotide transport by the reconstituted mitochondrial ADP/ATP carrier. Proc. Natl. Acad. Sci. USA.93: 664-668

31. Nelson DR, Felix CM and Swanson JM (1998) Highly conserved charge-pair networks in the mitochondrial carrier family. J. Mol. Biol. 277: 285-308
32. Oettmeier W, Masson K and Kalinna S (1995) $\left[{ }^{3} \mathrm{H}\right]$ 7-azido-4-isopropylacrione labels Cys159 of the bovine mitochondrial ADP/ATP-carrier protein. Eur. J. Biochem. 227: 730-733

33. Halestrap AP, Woodfield KY and Connern CP (1997) Oxidative stress, thiol reagents, and membrane potential modulate the mitochondrial permeability transition by affecting nucleotide binding to the adenine nucleotide translocase. J. Biol. Chem. 272: 3346-3354

34. Hashimoto M, Majima E, Hatanka T, Shinohara Y, Onishi M, Goto S and Terada $H(2000)$ Irreversible extrusion of the first loop facing the matrix of the bovine heartmitochondrial ADP/ATP carrier by labeling the Cys 56 residue with the $\mathrm{SH}$ reagent methyl methanethiosulfonate. J. Biochem. 127: 443-449

35. Hashimoto M, Majima E, Goto S, Shinohara Y and Terada H (1999) Fluctuation of the first loop facing the matrix of the mitochondrial ADP/ATP carrier deduced from intermolecular cross-linking of Cys56 residues by bifunctional dimaleimides. Biochemistry 38: 1050-1056

36. Rück A, Dolder M, Wallimann T and Brdiczka D (1998) Reconstituted adenine nucleotide translocator forms a channel for small molecules comparable to the mitochondrial permeability transition pore. FEBS Lett. 426: 97-101

37. Marzol, Brenner C, Zamzami N, JürgensmeierJ, Susin SA, Vieira HLA, Prévost M-C, Xie Z, Mutsiyama S, Reed JC and Kroemer G (1998) Bax and adenine nucleotide translocator cooperate in the mitochondrial control of apoptosis. Science 281: 2027-2031

38. Costantini P, Belzacq A-S, Vieira HLA, Larochette N, de Pablo M, Zamzami N, Susin SA, Brenner Cand Kroemer G (2000) Oxidation of a critical thiol residue of the adenine nucleotide translocator enforces Bcl-2-independent permeability transition pore opening and apoptosis. Oncogene 19: 307-314

39. JacototE, Ravagnan L, Loeffler M, Ferri KF, Vieira HLA, Zamzami N, Costantini P, Druillennec S, Hoebeke J, Brian JP, Irinopoulos T, Daugas E, Susin SA, Cointe D, Xie ZH, Reed JC, Roques BP and Kroemer G (2000) The HIV-1 viral protein $\mathrm{R}$ induces apoptosis via a direct effect on the mitochondrial permeability transition pore. J. Exp. Med. 191: 33-45

40. Dierks T, Salenin A, Heberger C and Krämer R (1990) The mitochondrial aspartate/glutamate and ADP/ATP carrier switch from obligate counter exchange to unidirectional transport after modification by $\mathrm{SH}$-reagents. Biochim. Biophys. Acta. 1028: 268-280

41. González Barroso MM, Fleury C, Levi Meyrueis C, Zaragoza P, Bouillaud F and Rial E (1997) Deletion of amino acids 261-269 in the brown fat uncoupling protein converts the carrier protein into a pore. Biochemistry 36: 10930-10935

42. Brustovetsky N and Klingenberg M (1996) Mitochondrial ADP/ATP carrier can be reversibly converted into a large channel by $\mathrm{Ca2}+$. Biochemistry 35 : 8483 8488

43. Brenner C, Cardiou H, Vieira HLA, Zamzami N, Marzo I, Xie Z, LeberB, Andrews D, Duclohier H, Reed JC and Kroemer G (2000) Bcl-2 and Bax regulate the channel activity of the mitochondrial adenine nucleotide translocator. Oncogene 19: 329-336

44. Ying XM, Oltvai ZN and Korsmeyer SJ (1994) BH1 and BH2 domains of Bcl-2 are required for inhibition of apoptosis and heterodimerization with Bax. Nature 369: $321-323$

45. Matsuyama S, Schendel SL, Xie Z and Reed JC (1998) Cytoprotection by Bcl-2 requires the pore-forming alpha 5 and alpha 6 helices. J. Biol. Chem. 273: 30995-31001

46. Schendel S, Xie Z, Montal MO, Matsuyama S, Montal M and Reed JC (1997) Channel formation by antiapoptotic protein Bcl-2. Proc. Natl. Acad. Sci. USA. 94: 5113-5118

47. Marzo I, Brenner C, Zamzami N, Susin SA, Beutner G, Brdiczka D, Rémy R, Xie Z-H, Reed JC and Kroemer G (1998) The permeability transition pore complex: a target for apoptosis regulation by caspases and $\mathrm{Bcl}-2$ related proteins. J. Exp. Med. 187: 1261-1271

48. Khaspekov L, Friberg H, Halestrap A, Viktorov I and Wieloch T (1999) Cyclosporin $\mathrm{A}$ and its nonimmunosuppressive analogue N-Me-Val-4cyclosporin A mitigate glucose/oxygen deprivation-induced damage to rat cultured hippocampal neurons. Eur. J. Neurosci. 11: 3194-3198

49. Woodfield K, RuckA, Brdiczka D and Halestrap AP (1998) Direct demonstration of a specific interaction between cyclophilin- $D$ and the adenine nucleotide translocase confirms their role in the mitochondrial permeability transition. Biochem. J. 336: 287-290 
50. Crompton M, Virji S and Ward JM (1998) Cyclophilin-D binds strongly to complexes of the voltage-dependent anion channel and the adenine nucleotide translocase to form the permeability transition pore. Eur.J. Biochem. 258:729 735

51. Connern CP and Halestrap AP (1996) Chaotropic agents and increased matrix volume enhance binding of mitochondrial cyclophilin to the inner mitochondrial membrane and sensitize the mitochondrial permeability transition to $\mathrm{Ca} 2+$ Biochemistry 35: 8172-8180

52. Narita M, Shimizu S, Ito T, Chittenden T, Lutz RJ, Matsuda H and Tsujimoto $Y$ (1998) Bax interacts with the permeability transition pore to induce permeability transition and cytochrome c release in isolated mitochondria. Proc. Natl. Acad. Sci. USA. 95: 14681-14686

53. Buhler S, Michels J, Wendt S, Ruck A, Brdiczka D, Welte W and Przybylski M (1998) Mass spectrometric mapping of ion channel proteins (porins) and identification of their supramolecular membrane assembly. Protein Structure Function Gen. S2: 63-73

54. Voehringer DW, Hirschberg DL, Xiao J, Lu Q, Roederer M, Lock CB, Herzenberg LA, Steinman L and Herzenberg LA (2000) Gene microarray identification of redox and mitochondrial elements that control resistance or sensitivity to apoptosis. Proc. Natl. Acad. Sci. USA. 97: 2680-2685

55. McEnery MW, Snowman AM, Trifiletti RR and Snyder SH (1992) Isolation of the mitochondrial benzodiazepine receptor: Association with the voltagedependent anion channel and the adenine nucleotide carrier. Proc. Natl. Acad. Sci. USA. 89: 3170-3174

56. Pastorino JG, Simbula G, Yamamoto K, Glascott PAJ, Rothman RJ and Farber JL (1996) The cytotoxicity of tumor necrosis factor depends on induction of the mitochondrial permeability transition. J. Biol. Chem. 271: 29792-29799

57. Hirsch T, Decaudin D, Susin SA, Marchetti $P$, Larochette N, Resche-Rigon M and Kroemer G (1998) PK11195, a ligand of the mitochondrial benzodiazepin receptor, facilitates the induction of apoptosis and reverses Bcl-2-mediated cytoprotection. Exp. Cell. Res. 241: 426-434

58. Larochette N, Decaudin D, Jacotot E, Brenner C, Marzo I, Susin SA, Zamzami $\mathrm{N}$, Xie Z, Reed JC and Kroemer G (1999) Arsenite induces apoptosis via a direct effect on the mitochondrial permeability transition pore. Exp. Cell. Res. 249: 413-421

59. Ravagnan L, Marzo I, Costantini P, Susin SA, Zamzami N, Petit PX, Hirsch F, Poupon M-F, Miccoli L, Xie Z, Reed JC and Kroemer G (1999) Lonidamine triggers apoptosis via a direct, Bcl-2-inhibited effect on the mitochondrial permeability transition pore. Oncogene 18: 2537-2546

60. Beutner G, Ruck A, Riede B and Brdiczka D (1998) Complexes between porin, hexokinase, mitochondrial creatine kinase and adenylate translocator display properties of the permeability transition pore. Implication of regulation of permeability transition by the kinases. Biochim. Biophys. Acta - Biomembr. 1368: 7-18

61. Kanazawa A, Tanaka A, Iwata S, Satoh S, Hatano E, Shinohara H, Kitai T, Tsunekawa S, Ikai I, Yamamoto M, Takahashi R, Chance B and Yamaoka Y (1998) The beneficial effect of phosphocreatine accumulation in the creatine kinase transgenic mouse liver in endotoxin-induced hepatic cell death. J. Surg Res. 80: 229-235

62. Klivenyi P, Ferrante RJ, Matthews RT, Bogdnaow MB, Klein AL, Andrassen OA, Mueller G, Wermer M, Kaddurah-Daouk R and Beal F (1999) Neuroprotective effects of creatine in a transgenic animal model of amyotrophic lateral sclerosis. Nature Med. 5: 347-350

63. Sigal CT and Resh MD (1993) The ADP/ATP carries is the 32-kilodalton receptor for an $\mathrm{NH} 2$-terminally myristylated src peptide but not for pp60src polypeptide. Mol. Cell. Biol. 13: 3084-3092

64. Goldmacher VS, Bartle LM, Skletskaya S, Dionne CA, Kedersha NL, Vater CA, Han JW, Lutz RJ, Watanabe S, McFarland EDC, Kieff ED, Mocarski ES and Chittenden T (1999) A cytomegalovirus-encoded mitochondria-localized inhibitor of apoptosis structurally unrelated to Bcl-2. Proc. Natl. Acad. Sci. USA. 96: $12536-12541$

65. Zamzami N, Marzo I, Susin SA, Brenner C, Larochette N, Marchetti P, Reed J Kofler R and Kroemer G (1998) The thiol-crosslinking agent diamide overcomes the apoptosis-inhibitory effect of $\mathrm{Bcl}-2$ by enforcing mitochondrial permeability transition. Oncogene 16: 1055-1063

66. Hermesh O, Kalderon B and Bar Tana J (1998) Mitochondrial uncoupling by a long chain fatty acyl analogue. J. Biol. Chem. 273: 3937-3942

67. Skulachev VP (1999) Anion carriers in fatty acid-mediated physiological uncoupling. J. Bioenerg. Biomembr. 31: 431-435
68. de Pablo M, Susin SA, Jacotot E, Larochette N, Costantini P, Ravagnan L, Zamzami N, and Kroemer G (1999) Palmitate induced apoptosis via a direct effect on mitochondria. Apoptosis 4: 81-87

69. Moreno Sanchez R, Bravo C, Vasquez C, Ayala G, Silveira LH and Martinez Lavin M (1999) Inhibition and uncoupling of oxidative phosphorylation by nonsteroidal anti-inflammatory drugs. Study in mitochondria, submitochondrial particles, and whole cells. Biochem. Pharmacol. 57: 743-752

70. Chen JI, Bertrand H and Yu BP (1995) Inhibition of adenine-nucleotide translocator by lipid peroxidation products. Free Radical Biol. Med. 19: 583590

71. Harris MH, Vander Heiden MG, Kron SJ and Thompson CB (2000) Role of oxidative phosphorylation in Bax toxicity. Mol. Cell. Biol. 20: 3590-3596

72. Matsuyama S, Xu Q, Velours J and Reed JC (1998) Mitochondrial F0F1. ATPase proton pump is required for function of proapoptotic protein Bax in yeast and mammalian cells. Mol. Cell. 1: 327-336

73. Bauer MKA, Schubert A, Rocks O and Grimm S (1999) Adenine nucleotide translocase-1, a component of the permeability transition pore, can dominantly induce apoptosis. J. Cell. Biol. 147: 1493-1501

74. Bou Hamdan M, Xue Y, Baudat Y, Hu B, Sire J, Pomerantz RJ and Duan LX (1998) Diversity of HIV-1 Vpr interactions involves usage of the WXXF motif of host cell proteins. J. Biol. Chem. 273: 8009-8016

75. Vander Heiden MG, Chandal NS, Williamson EK, Schumacker PT and Thompson CB (1997) Bcl-XL regulates the membrane potential and volume homeostasis of mitochondria. Cell 91: 627-637

76. Matsuyama S, Llopis J, Deveraux QL, Tsien RY and Reed JC (2000)Changes in intramitochondrial and cytosolic $\mathrm{pH}$ : early events that modulate caspase activation during apoptosis. Nature Cell Biol. 2: 318-325

77. Vander Heiden MG, Chandel NS, Li XX, Schumacker PT, Columbini M and Thompson CB (2000) Outer mitochondrial membrane permeability can regulate coupled respiration and cell survival. Proc. Natl. Acad. Sci. USA. 97: 4666-4671

78. Angermuller S, Kunstle $G$ and Tiegs $G$ (1998) Pre-apoptotic alterations in hepatocytes of TNF alpha-treated galactosamine-sensitized mice. J. Histochem. Cytochem. 46: 1175-1183

79. Teranishi M, Karbowski M, Kurono C, Soji K and Wakabayashi T (1999) Two types of the enlargement of mitochondria related to apoptosis: simple swelling and the formation of megamitochondria. J. Electron Microsc. 48: 637-651

80. Guastadisegni C, Balduzzi M, Mancuso MT and DiConsiglio E (1999) Liver mitochondria alterations in chloroform-treated Sprague-Dawley rats. J. Toxicol. Environm. Health 57: 415-429

81. Kwong J, Choi HL, Huang Y and Chan FL (1999) Ultrastructural and biochemical observations on the early changes in apoptotic epithelial cells of the rat prostate induced by castration. Cell Tissue Res. 298: 123-136

82. Buki A, Onkonkwo DO, Wang KKW and Pavlishock JT (2000) Cytochrome c release and caspase activation in traumatic axonal injury. J. Neurosci. 20: $2825-2834$

83. Sun YD, Clinkenbeard KD, Ownby CL, Cudd L, Clarke CR and Highlander SK (2000) Ultrastructural characterization of apoptosis in bovine lymphocytes exposed to Pasteurella haemolytica leukotoxin. Am. J. Vet. Res. 61:51-56

84. Madesh M, Ramachandran A, Pulimooed A, Vadranam M and Balasubramanian KA (2000) Attenuation of intestinal ischemia/reperfusion injury with sodium nitroprusside: studies on mitochondrial function and lipid changes. Biochim. Biophys. Acta. 1500: 204-216

85. Hirose K, Westrum IE, Stone JS, Zirpel Land RubelEW (1999) Dynamic studies of ototoxicity in mature avian auditory epithelium. Ann. NY Acad. Sci. 884: 389 409

86. Rippo MR, Malisan F, Ravagnan L, Condo I, Tomassini B, Costantini P, Todaro M, Susin SA, Rufini A, Kroemer G and Testi R (2000) Ganglioside GD3 directly targets mitochondria and induces the release of apoptogenic factors. FASEBJ. 14: 2047-2054

87. Robb SJ, Gospers LD, Wright KJ, Thomas AP and Connor JR (1999) Influence of nitric oxide on cellular and mitochondrial integrity in oxidatively stressed astrocytes. J. Neurosci. Res. 56: 166-176

88. Ferrand Drake M, Friberg $\mathrm{H}$ and Wieloch $\mathrm{T}$ (1999) Mitochondrial permeability transition induced DNA-fragmentation in the rat hippocampus following hypoglycemia. Neuroscience 90: 1325-1338

89. Okuno S, Shimizu S, Ito T, Nomura M, Hamada E, Tsujimoto $Y$ and Matsuda H (1998) Bcl-2 prevents caspase-independent cell death. J. Biol. Chem. 273: 34272-34277 
90. Sugimoto T, Xiao C and Ichikawa H (1998) Neonatal primary neuronal death induced by capsaicin and axotomy involves an apoptotic mechanism. Brain Res. 807: 147-154

91. Antonsson B, ContiF, CiavattaA, MontessuitS, Lewis S, Martinou I, Bernasconi M, Bernard A, Mermod J-J, Mazzei G, Maundrell K, Gambale F, Sadoui R and Martinou J-C (1997) Inhibition of Bax channel-forming activity by Bcl-2. Science 277: $370-376$

92. Schlesinger PH, Gross A, Yin XM, Yamamoto K, Saito M, Waksman G and Korsmeyer SJ (1997) Comparison of the ion channel characteristics of proapoptotic Bax and antiapoptotic Bcl-2. Proc. Natl. Acad. Sci. USA. 94: $11357-11362$

93. Shimizu S, Konishi A, Kodama T and Tsujimoto $Y$ (2000) BH4 domain of antiapoptotic Bcl-2 family members closes voltage-dependent anion channel and inhibits apoptotic mitochondrial changes and cell death. Proc. Natl. Acad. Sci. USA 97: 3100-3105

94. Marchetti P, Castedo M, Susin SA, Zamzami N, Hirsch T, Haeffner A, Hirsch F Geuskens M and Kroemer G (1996) Mitochondrial permeability transition is a central coordinating event of apoptosis. J. Exp. Med. 184: 1155-1160

95. Marchetti P, Hirsch T, Zamzami N, Castedo M, Decaudin D, Susin SA, Masse B and Kroemer $G$ (1996) Mitochondrial permeability transition triggers lymphocyte apoptosis. J. Immunol. 157: 4830-4836

96. Doi T, Motoyama N, Tokunaga A and Watanabe T (1999) Death signals from the $B$ cell antigen receptor target mitochondria, activating necrotic and apoptotic death cascades in a murine B cell line, WEHI-231. Int. Immunol. 11: 933-941

97. Hehner SP, Hofmann TG, Ratter F, Dumont A, Dröge W and Schmitz ML (1998) Tumor necrosis factor-alpha induced cell killing and activation of transcription factor NF-kappa B are uncoupled in L929 cells. J. Biol. Chem. 273: 1811718121

98. Pastorino JG and Hoeck JB (2000) Ethanol potentiates tumor necrosis factoralpha cytotoxicity in hepatoma cells and primary rat hepatocytes by promoting induction of the mitochondrial permeability transition. Hepatology 31: 11411152
99. Watson RWG, O'Neill A, Brannigen AE, Coffey R, Marshall JC, Brady HR and Fitzpatrick JM. (1999) Regulation of Fas antibody induced neutrophil apoptosis is both caspase and mitochondrial dependent. FEBS Lett. 453: 67-71

100. Dumont A, Hehner SP, Hofmann TG, Ueffing M, Droge W and Schmitz ML (1999) Hydrogen peroxide-induced apoptosis is CD95-independent, requires the release of mitochondria-derived reactive oxygen species and the activation of NF-kappa B. Oncogene 18: 747-757

101. Fulda S, Scaffidi C, Susin SA, Krammer PH, Kroemer G, Peter ME and Debatin $\mathrm{KM}$ (1998) Activation of mitochondria and release of mitochondrial apoptogenic factors by betulinic acid. J. Biol. Chem. 273: 33942-33948

102. Furlong IJ, Lopez Medivilla C, Ascaso R, Lopez Rivas A and Collins MKL (1998) Induction of apoptosis by valinomycin: mitochondrial permeability transition causes intracellular acidification. Cell Death Differ. 5: 214-221

103. Budd SL, Tenneti L, Lishnak T and Lipton SA (2000) Mitochondrial and extramitochondrial apoptotic signaling pathways in cerebrocortical neurons. Proc. Natl. Acad. Sci. USA. 97: 6161-6166

104. Stridh H, Fava E, SingleB, Nicotera P, Orrenius S and Leist M (1999) Tributyltininduced apoptosis requires glycolytic adenosine triphosphate production. Chem. Res. Toxicol. 12: 874-882

105. Sakai H, Kobayashi Y, Sakai E, Shibata M and Kato Y (2000) Cell adhesion is a prerequisite for osteoclast survival. Biochem. Biophys. Res. Commun. 270: $550-556$

106. Mastrangelo AJ, Zou SF, Hardwick JM and Betenbaugh MJ (1999) Antiapoptosis chemicals prolong productive lifetimes of mammalian cells upon Sindbis virus vector infection. Biotechnol. Bioengineering 65: 298-305 